\title{
Risk-reducing mastectomy in BRCA mutation carriers: survival is one of the issues-author's reply
}

\author{
Bernadette Anna Maria Heemskerk-Gerritsen ${ }^{1}\left[\right.$ D $\cdot$ Maartje Joanneke Hooning ${ }^{1}$
}

Received: 13 October 2019 / Accepted: 28 October 2019 / Published online: 6 November 2019

○) Springer Science+Business Media, LLC, part of Springer Nature 2019

Words can do a lot of harm. One wrong headline in the lay press, shared on social media, can lead to a lot of misery. Misery for the women who underwent preventive breast surgery in the past and now could read in the news that this drastic operation may have been unnecessary. Misery for all dedicated clinicians who had to reassure these women that they had made the right decision, and also frustration for all investigators involved in the original paper who saw their message being framed so wrongly.

We recently reported lower overall and breast cancer-specific mortality rates among $B R C A 1$ mutation carriers opting for bilateral risk-reducing mastectomy (BRRM) than among those under surveillance. For BRCA2 mutation carriers, BRRM was non-significantly associated with lower overall mortality when compared with surveillance. Additionally, we observed more favorable characteristics of BRCA2-associated breast tumors, which eventually may lead to comparable breast cancer-specific mortality rates after either BRRM or surveillance. We concluded that our findings may support a more individualized counseling, based on BRCA mutation type, regarding the difficult choice between BRRM and breast cancer surveillance [1].

We certainly did not conclude that women carrying a BRCA2 mutation should be informed that BRRM is an over-treatment, as was presumed by Neven et al. [2]. Indeed, to our great dismay the results of our study have been distorted in the Dutch newspaper Algemeen Dagblad edition 29/07/2019 with the headline "Preventive breast surgery appears not to be necessary", as already noted by Evans et al. [3].

This Rebuttal letter refers to the Letter to the editor article available at https://doi.org/10.1007/s10549-019-05440-4.

Bernadette Anna Maria Heemskerk-Gerritsen

b.heemskerk-gerritsen@erasmusmc.nl

1 Erasmus MC Cancer Institute, Rotterdam, The Netherlands
We understand and share the concern of our colleagues from Leuven and Manchester that our message was framed so wrongly in the lay press and thus has upset many women and their physicians. Immediately after the appearance of the news article, we and colleagues from several medical centers and from patient advocate groups have been busy in all kinds of media-radio, television, newspapers, websites for $B R C A$ mutation carriers-to unnerve the headline and reassure women that their decision to opt for BRRM to prevent breast cancer was a right decision-as is the decision of other women to remain under intensive surveillance.

In the current counseling process, BRRM and surveillance are discussed as two reasonable options for healthy BRCA1/2 mutation carriers. The wish to avoid a breast cancer diagnosis and resultant treatment and the anxiety related to the frequent and ongoing surveillance-with unchanged high breast cancer risks-are recognized as the main reasons for women to decide for BRRM. Thus far, mortality rates have had no significant impact on the decision processprobably also because reliable figures were lacking. In this study, we showed that for BRCAl mutation carriers' life expectancy is somewhat higher after BRRM. In our opinion, this finding may be relevant in the difficult individual decision-making process between both options.

On behalf of all co-authors,

B.A.M. Heemskerk-Gerritsen and M.J. Hooning

\section{References}

1. Heemskerk-Gerritsen BAM, Jager A, Koppert LB, Obdeijn AI-M, Collée M, Meijers-Heijboer HEJ, Jenner DJ, Oldenburg HSA, van Engelen K, de Vries J, van Asperen CJ, Devilee P, Blok MJ, Kets CM, Ausems MGEM, Seynaeve C, Rookus MA, Hooning MJ (2019) Survival after bilateral risk-reducing mastectomy in healthy BRCA1 and BRCA2 mutation carriers. Breast Cancer Res Treat 177(3):723-733 
2. Neven P, Punie K, Wildiers H, Willers N, Van Ongeval C, Van Buggenhout G, Legius E (2019) Risk-reducing mastectomy in BRCA carriers: survival is not the issue. Breast Cancer Res Treat

3. Evans DG, Howell SJ, Howell A (2019) Should unaffected female BRCA2 pathogenic variant carriers be told there is little or no advantage from risk reducing mastectomy? Fam Cancer 18(4):377-379
Publisher's Note Springer Nature remains neutral with regard to jurisdictional claims in published maps and institutional affiliations. 